\title{
The Reflection and Rebuilding of the Enterprise Value Chain Mode in the Network Trading Environment Based on the Value Network
}

\author{
Huabai Bu \& Yang Gao \\ Hengyang Normal University, Hengyang 421008, China \\ Business School of Central South University, Changsha 410083, China \\ E-mail: buhuabai@163.com
}

The research is supported by the middle result of the project of "Study on the Drive Model and Simulation of the Enterprise Value Network Intergrowth Evolvement" of the Hunan Provincial Natural Science Fund (No. 10JJ3098) and the middle result of the project of "Study on the Cluster Enterprise Value Chain Intergrowth Evolvement in the Total Crisis Background" of the Hunan Provincial Science and Technology Department Soft Science Research (No. 2009KZ3096) and the middle result of the project of "Study on the Frangibility of the Complex Adaptive System of Enterprise Value Network" of the Hunan Provincial Education Department Research Project (No. 09C192) and the middle result of the project of the China Natural Science Fund (No. 71071163). (Sponsoring information)

\begin{abstract}
The operation limitations of the value chain have occurred in the Internet times obvious, and the value network is a new concept to develop the useful and discard the useless for the value chain. As the new concept, the value network has been a leading concept in the world. Based on the analysis of the limitations of the value chain, the new research results of the value network in the theoretical and industrial cycle are referenced to put forward the concept model of rebuilding the value chain based on the value network in the network trading environment, which could provide theoretical references for enterprises to quickly enhance the service speed, respond the market, offer individualized products, and increase the consumer value in the new business environment.
\end{abstract}

Keywords: Network trading, Value chain, Value network, Limitations, Rebuilding

\section{Introduction}

The survival of the fittest is the conclusion of about 200 years' biological research. And this conclusion tells us that the important reason of biological species evolvement is that the interior characteristics of biological species should adapt the change of exterior environment. Enterprises also have biological characteristics, and these characteristics determine that enterprises would continually evolve because of the environment, according with the principle of the survival of the fittest. In 1985, Baud put forward the value chain operation mode of enterprise, and undeniably, this mode had played important role for enterprise to enhance the comprehensive competitive force, but up to now, the environment of the enterprise value chain operation mode has changed profoundly, which makes enterprise to face a new consumer environment factor and operation platform factor for the market trading and the organization relationship, i.e. the consumer trading mode is turning from the traditional shop trading to the network trading, with the networking and digitalized operation platform among enterprises, and this new environmental factor makes the operation mode of enterprise value chain have large limitation, and the effective operation of the enterprise value chain is encountering the "block" which could not be rounded. The concept of the value network first occurred in Adrian J. Slywotzky and David J. Morrison's book of "Discover the Profit Region" from Mercer Consultant Company, and David Bovet further developed this concept as a business operation mode, and up to now, the value network has been a leading concept in the world to develop the useful and discard the useless of the value chain, and quickly been the hotspot in the theoretical research. In the book of "Opening Growth of Commercial Trend: From Value Chain to Value Network", Linda S. Sanford, the global vice president of IBM, pointed out that the development from value chain to value network was the big tendency of the commercial development. For the present theoretical cycle and the industrial cycle, a practical difficulty is what limitations in the value chain operation mode should be discarded by the value network, and how the value chain should be changed to be the value network.

\section{The network trading environment: the "block" of the effective operation of the enterprise value chain mode}

Up to the late of June of 2010, the network people of China continually increase, and the total size of network people had achieved 0.42 billion, increasing 36 million comparing with the number in the late of 2009 . And the popularity rate of Internet has ascended to $31.8 \%$, an increase of $2.9 \%$ comparing with the number in the late of 2009. The network people of China had exceeded than US in the June of 2008, ranking the first in the world, the 
internet polarizing rate of China has exceeded the global average level, and the concrete change is seen in Figure 1.

Up to June of 2010, the size of network shopping user had achieved 0.142 billion and the use rate had been increased to $33.8 \%$, an increase of $5.7 \%$, and the half-year use growth achieved $31.4 \%$. The quick growth of the network shopping user size shows the powerful development tendency of the electrical commercial market of China.

From above data, the network trading is being popularized, and the environment of network trading is being formed. At the same time, the quick development of Internet technology further strengthens the change of the environment. The Academician Li Guojie of Chinese Science Academy thought that if the first-generation Internet realized the link of computer hardware and induced the first Internet tide, and the second-generation Internet Web realized the link of web pages and induced the second Internet tide, so the third-generation Internet Grid could realize the comprehensive link of all resources on the Internet and induce the third Internet tide, and its direct result was that the realization of the business "changing with the demands", which would further induce the profound change of the network trading environment, and large limitations in the enterprise value chain operation mode, and the effective management of the enterprise value chain would encounter the "block" which was difficult to overcome.

\section{Limitations of the enterprise value chain operation mode in the network trading environment}

In the new business environment, traditional value chain mode has following limitations. First, because of the complex fluctuation and incomplete controllability, any prediction tools and measures could not exactly predict the real supply and demand in the product market and the factor market, and the traditional enterprise value chain mode could not really match the demand and the supply, and consumers' individuality demands could not be satisfied. Second, the popularization and use of the electrical business technology impact the sales mode in the product market and the factor market, impact consumers' purchase mode, and influence consumers' shopping behaviors, and the marketing mode in the traditional value mode has not been adapted. Third, the value chain mode only provide the products and services for all consumers by single production and distribution flow, and consumers' special value claims are difficultly satisfied, and at the same time, the interior resources and abilities could not be effectively harmonized and integrated with exterior resources and abilities of enterprises, and the core production capacities among enterprises could not be compensated each other, and enterprises could not quickly response the demand of the market. Though the competitors of enterprise have been considered in the analysis of the value chain, but those compensators who play more and more important roles in the creation of enterprise value have not been considered, so the traditional value chain analysis is limited largely. Fourth, the "bullwhip effect" obviously exists in the value chain operation mode, which could not only amplify the warps of the value chain information flow, the logistical flow, and the capital flow among the chain, and induce the failure of decision, but also increase the total stock cost of the chain, and break the nodes of the value chain of the linear relationship among enterprises because of emergencies. At the same time, the rigid supply structure of the value chain mode could not realize the flexible output and production, and especially, when the demand is customized for solutions or individualization, the value chain mode is useless.

Through above analysis, the operation mode of value chain is limited in the new enterprise operation mode, but the operation mode of value network could improve this limitation, because it is more advantageous than the traditional value chain.

(1) Consumers actively trigger the value network, and enterprises could obtain real demand information.

Consumers' demand could directly trigger the order, production, and distribution in the value network, but traditionally, enterprises trigger the value chain, and change the trading state that consumers passively concept the output result of the value chain, and consumers' dominant state could be confirmed, and consumers' demand information could be also confirmed, so the value network could integrate consumers' front-end demand and after-end demand, so the production of enterprise is based on consumers' real demand, which could reduce the market risk and enhance consumers' satisfaction, because enterprises would not predict the market according to their own ideas.

(2) Because of the real-time cooperation in the total value network, consumers' demand could be responded quickly.

In the value network creating values, enterprises must cooperate with consumers, cooperative fellows, even competitors, and they could appoint the fittest cooperative fellows to communicate and harmonize with their departments by the business cooperation system, and ensure that the value network could quickly respond consumers' demand change, and produce the maximum consumer's benefit in the total value network. At the same time, the real-time cooperation of the total value network could also reduce the stock level of small enterprises, and reduce the negative influences of the "bullwhip effect".

(3) Digital transfer could quickly integrate and adjust the resources among enterprises.

Traditional value chains use analog transfer mode, but the value network uses the digital transfer mode, so 
consumers, enterprises, and other cooperative companies could harmonize resources among them in time, and the work period from consumers' order to enterprises' delivery is reduced obviously, and the capital flow speed is increasing.

In a word, the enterprise value network has six basic competitive advantages such as network economy, scale economy, risk counterwork, viscous effect, complementary effect, and speed effect, so in the network trading environment, enterprises should change the past operation mode of value chain from the strategic view.

\section{Rebuilding of the enterprise value chain operation model in the network trading environment: an analysis view based on the value network}

\subsection{The concept model to rebuild the enterprise value chain based on the value network in the network trading environment}

There are three intentions for enterprises to change the value chain to the value network. The first one is to enhance enterprises' ability of quickly responding the market. The second one is to enhance enterprises' ability of quickly providing individualized products, increasing customer value, and increasing customer satisfaction. The third one is to enhance enterprises' ability of adapting the operation environment of networking trade and enhancing the core competitive force of enterprises. In the network trading environment, these three intentions could be realized by establishing the following enterprise value chain rebuilding concept model, and the concrete rebuilding content is seen in Figure 3.

From above concept model figure, the rebuilt value network mainly includes three core network sub-systems, i.e. the client result network, the interior operation network, and the cooperative supply network among enterprises, and these three network sub-systems also are the core content to rebuild the network chain based on the value network for enterprises.

The main characters that the value network differentiates with the traditional value chain are embodied as follows. First, it could embody consumers' real demand by the client resource network, so the problems such as the matching problem of product supply and demand, and the problem that consumers' individualized demand could not be satisfied in traditional enterprise value chain mode could be improved here. Second, it could harmonize the interior operations in the enterprise in the enterprise by the interior operation network, and quickly translate consumers' demand into practical supply. Third, it could realize the digitalized transfer among enterprises by the cooperative supply network, and the resources among enterprises could be quickly integrated and adjusted, one-way project of the value chain could be rebuilt as the parallel-way project of the value network, and enterprises' response speed for customers' demand will be enhanced relatively, and the resource utilization of enterprises will be more filled.

\subsection{Countermeasures to rebuild the enterprise value chain based on the value network in the network trading environment}

The concept model in the above network trading environment could offer the methodology for enterprises to change traditional value chain. In the concrete rebuilding process, first, the senior layer of the enterprise must recognize the objective inevitability of the rebuilding, and pay more attention to this rebuilding for the strategic layer, which is the base and premise of successful rebuilding. Second, the concrete countermeasures to rebuild the value chain according to three network sub-systems of the value network include following aspects.

\subsubsection{Start from the consumers' value demands to rebuild the client resource network}

The client resource network is composed by the client, the channel, the client resources, and their mutual relations, and it is the core and drive of the rebuilt enterprise value network.

First, enterprises should research clients' value standard, define the value cognized by the market, and transfer the value opinion of enterprises.

Consumers' value standard could embody consumers' requirements for the design, the quality, the performance, the package, the safety, and the after-service of products, and these requirements could be realized by that representative clients participate in the production, distribution, and transfer of products. The intention to study clients' value standard is to define the value cognized by the market, and transfer this value to correct quasi-clients and clients by right and quick mode. The Italy auto manufacturer Fiat wanted to test the design effect of its new car Punto, it invited about 3000 potential consumers to participate in the discussion in the Fiat website. The result showed that Fiat could use lower cost to obtain target consumers' opinions about the new car, and design the auto which could really reflect consumers' favors. And for consumers, they obtained the autos what they really wanted.

Second, enterprises could collect consumers' value appeals stochastically in the internet and establish the network quick-response system of the enterprise. 
In the environment that network consumers become more and more, consumers would always seek relative trading information by the internet, and express their own individualized value demands to multiple enterprises, and enterprises should save and take client information in time, control more possible client contact points, and quickly response consumers' value demands. In virtue of the network, the Dell Company used the direct selling mode to make consumers to obtain the computer collocation what consumers really need, and Dell also created the myth of zero-stock production.

Third, enterprise should continually optimize the consumer information system, fully main the client relation, and protect enterprise consumer resource.

The marketing theory had already proved that the cost to seek a new consumer far exceeded the cost to keep an old consumer, so after the trading happens, enterprises must maintain the client relation. Based on the value network, following points should be emphasized. First, enterprises should establish the client consumption information feedback system, collect, and dispose consumers' complaints and opinions, and enhance consumers' satisfaction. Second, enterprises should continually optimize the consumer information system, and keep stable cooperative relationship with consumers, and let consumers comprehensively participate in the value creation of products. Third, comparing with other competitive products, enterprises should offer more value surplus for consumers, such as increasing the consciousness of obtaining consumers' value obtainment or expanding the evaluation of consumers' value obtainment.

\subsubsection{Strengthen the flexible operation to rebuild the supply cooperation network}

The supply cooperation network is the main factor to distinguish the value network from the value chain, including the competitors, the supplements, and the suppliers. The competitors here mean the current competitors, the potential competitors, and the substitute producers. The supplements mean the participators that those clients could purchase complementary products from them, and suppliers could sell complementary resources to them. The replacers induced in the value network mode could help enterprises to correctly understand the mutual dependence relationship in the business, because if participators are competitors to contest profits in traditional value chain mode, enterprises would pay more attention to the competition, not to seek the cooperative opportunity, and pay more attention to the "cake partition", not to seek the "intergrowth of cake". It is a kind of innovation of the traditional value chain mode to induce the supplements into the value network mode, because in the traditional market relation analysis, supplements are always neglected, but they are the necessary part for enterprises to offer the total service, and the "intergrowth body" among enterprises to create values for consumers, and with the continual change of the market environment, the supplements' role is more and more important. Therefore, enterprises must strengthen the flexibility, integrate the replacers and supplements into the supply system of middle products even the final products, promote enterprises to realize the dynamic matching between the production adjustment and the market demand fluctuation.

\subsubsection{Enhance the core competitive force of enterprise to rebuild the interior operation network of enterprise}

The enterprise interior operation network is formed in the series process that the enterprises translate the demand into the practical supply, including the production network, the information network, and the knowledge network. For the rebuilding of the production network and the information network, enterprises could rebuild the operation flows by introducing the software such as ERP. For the building of the knowledge network which is an invisible but important network for the development of enterprise, it could only be formed in the interior of the enterprise by establishing a good mechanism. In the practical rebuilding process of the interior operation network, enterprises must enhance the core competitive force, confirm the operation range and resource advantages of the enterprise, orient and select themselves to satisfy numerous consumers with obvious individualized demands, and increase the quick response ability by outsourcing or cooperative protocols, which are all the base of the interior network to run effectively, and the key points for enterprises to rebuild the value chain.

\section{Conclusions}

With the gradual popularization of the enterprise operation environment networking, the enterprise value chain mode is obviously limited, and the value network mode is a new concept to develop the useful and discard the useless, and it is the inherence and development of the value chain mode, and the optimal operation mode in the networking environment for enterprise. The rebuilding measures of the value chain mode in the networking environment in this article could offer new methodology for enterprise to change the value chain to the value network, help enterprises to quickly enhance the service speed, respond the market, quickly provide individualized products, increase the customer value, and offer a self-adaptive dynamic environment for interior members' "intergrowth evolvement" in the enterprise value network. However, when it solve the limitations in the value chain mode, it still face new difficulties and challenges such as the exogenous risk induced by the non-cooperative game 
among participators in the value network and the non-core resources of enterprises excessively depend exterior supports, which still is the urgent difficulty in the present theoretical cycle and the industry cycle.

\section{References}

Adrian J. Slywotzky, David J. Morrison, Lawrence H. Albertsetal \& Paul G. Clifford. (2000). Discover the Profit Region (1st Edition). Beijing: China Citic Press. Jan of 2000.

Bi, Xinhua, Li, Haili \& Zhang, Heda. (2009). Study on the Mobile Business Commercial Mode Based on Value Network. Commercial Research. No.1.

Bu, Huabai \& Li Gan. (2009). A Grid-based Business Model on Demand and Its Implementation Research. Journal of Hengyang Normal University. No.4.

CINIC. (2010). The $26^{\text {th }}$ China Internet Development Status Statistical Report. Beijing: China Internet Network Information Center. July of 2010.

Jiang, Jihai \& Long, Yong. (2009). Research on Netting Mechanism of Value Net Based on Modularization and Dynamic Capability. Science and Technology Management Research. No.1.

Jiang, Qiping. (2009). From Value Chain to Value Network, and the Death of Enterprise. Internet Weekly. March 5, 2009.

Linda Sanford \& Dave Taylor, interpreted by Liu Xi. (2008). Opening Growth of Commercial Trend: From Value Chain to Value Network (1st Edition). Beijing: Orient Press. Jan of 2008.

Sheng, Ge. (2009). Study on the Value Network System Construction and Operation Mode Based on Modularization. Industrial Technology \& Economy. No.5.

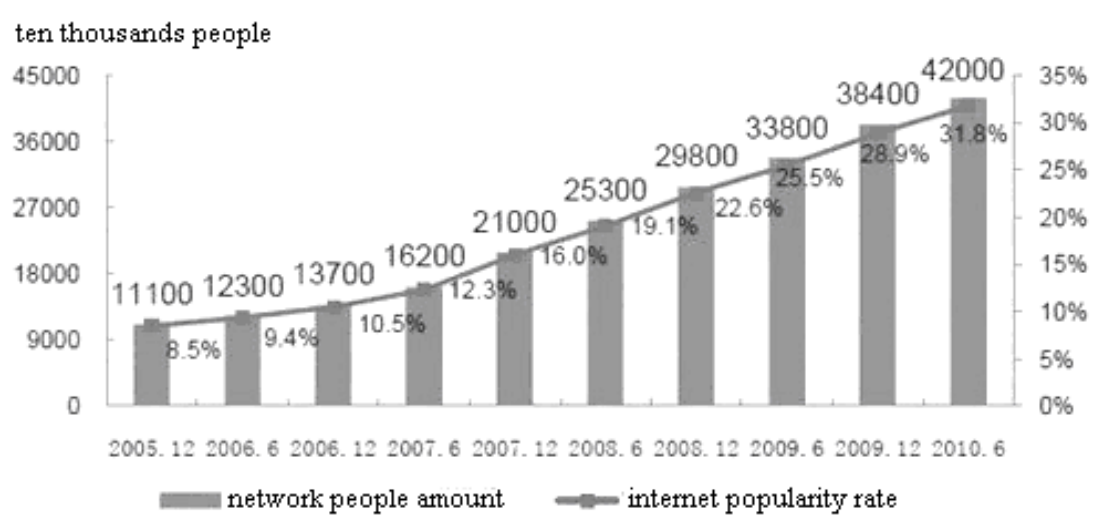

Figure 1. Change of China Network People Size and Yearly Growth Rate

Data from: The 26th China Internet Development Status Statistical Report, July of 2010. 


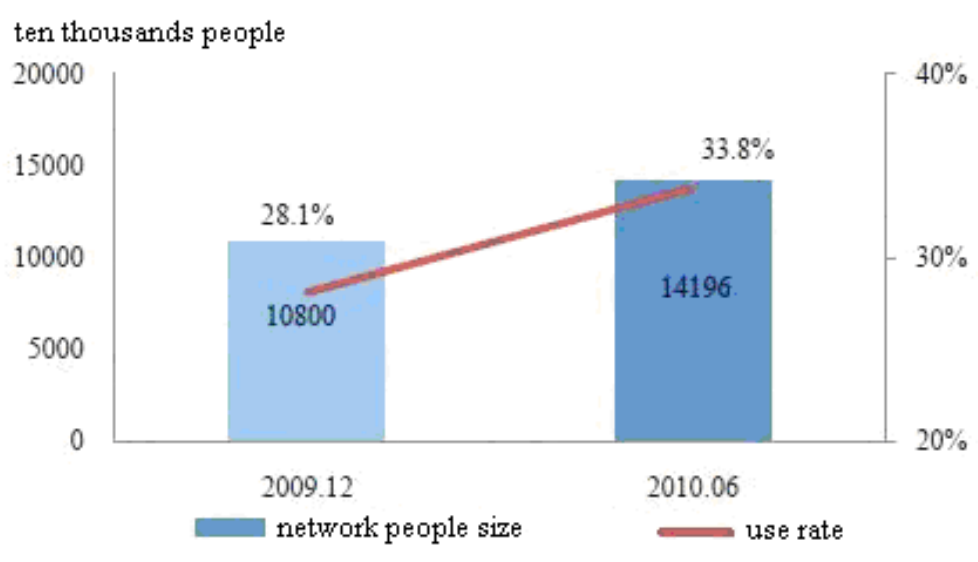

Figure 2. Change of China Network Shopping Amount and Yearly Growth Rate

Data from: The 26th China Internet Development Status Statistical Report, July of 2010.

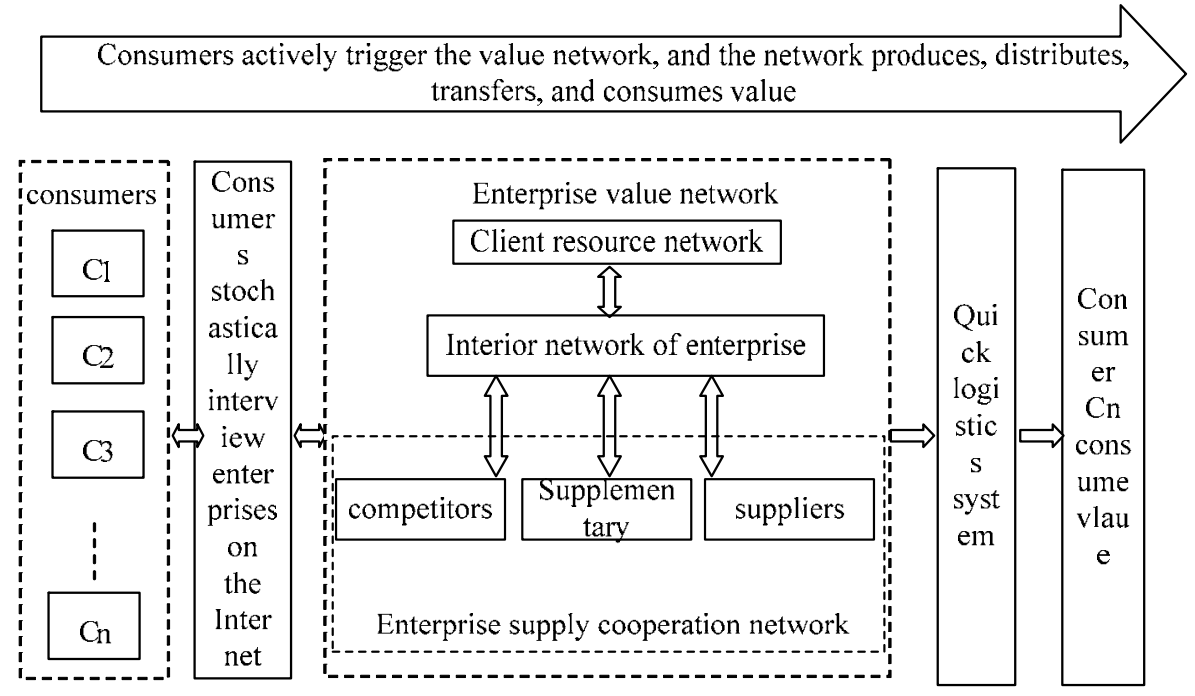

Figure 3. Concept Model of the Enterprise Value Chain Alteration in the Network Trading Environment 